\title{
HERITAGE MANAGAMENT AND URBAN DEVELOPMENT: CHALLENGES AND OPPERTUNITIES
}

\author{
$J$ Edirisinghe \\ Department of Estate Management and Valuation, \\ University of Sri Jayewarder epura, Nugegoda
}

The Built Heritage belongs to a particular country or nation whether it could be an ancient city, building or statute, is unique in location and creation. The value associated with it is incomparable due to this character. The built heritage is the link to past, although their original purpose has now gone. The historical bu *. form of a city is an inheritance of the legacy of history. It records a wealth of information on the development process as well as the wisdom and creativity of mankind. The cultural, aesthetic and spiritual values embodied in the built heritage are quite different from many other environmental resources.

The built heritage in urban areas is at a risk due to various disastrous problems, both natural and man-made. The so-called development both econom $c$ and physical has significant impact on heritage properties and may even be threaten with des ruction. It is important to take appropriate measures to conserve the built heritage in urban areas and face up to challenges from various directions. The crucial issue is to find ways and means to balance the development and conservation efforts. Though there is a consensus on the value of built heritage and rational for conservation, the dilemma is found on the clash between the objectives of development plans and conservation efforts. Urban development efforts in developing countries are faced with several challenges compared to the developed countries. Poverty, high rate of unemployment, urban informal sector, poor housing and infrasiructure are some of them. Under these circumstances the value of built heritage has been weighed only in the shadow of the financial benefits. It is noted that in some instances the econoric interests placed in urban development plans carry more value than the value of built heritag Besides these economic impacts, the complete negligence of conservation or absence of neritage management plans integrated with the urban development plans are the most common phenomena seen in developing countries.

The ideal situation which guarantee both the security of cultural properties and economic property is the formulation of heritage management ylans and urban development plans on the basis of mutually sustainable manner. This paper analyses the issues faced in conservation and management of urban built heritage in the process of urban development in developing countries. Similarly the potentials for integration of built heritage in the urban development process have been discussed. The necessary examples have been drawn from Sri Lanka to establish the facts. 